\title{
Formação da veia porta-hepática em coelhos da raça Nova Zelândia Branco (Oryctolagus cuniculus Linnaeus, 1758)
}

Arlei José BIRCK ${ }^{1}$

Maria Angelica MIGLINO²

Gilberto Valente

MACHADO $^{1}$

Tatiana Carlesso dos

SANTOS ${ }^{2}$

Correspondência para: ARLEIJOSÉBIRCK

Laboratório de Anatomia Universidade Federal do Paraná

Rua 24 de Junho, 689, Jardim Dallas 85950-000 - Palotina, PR

ajbirck@ig.com.br

Recebido para publicação: 18/03/2004 Aprovado para publicação:23/08/2005

1 - Laboratório de Anatomia da Universidade Federal do Paraná, Palotina - PR

2 - Departamento de Cirurgia da Faculdade de Medicina Veterinária e Zootecnia da Universidade de São Paulo, São Paulo - SP

\begin{abstract}
Resumo
Considerando a escassez de informações na literatura, buscou-se traçar um perfil de formação da veia porta-hepática em 20 coelhos, reconhecendo o padrão de sua formação extraparenquimal e as possíveis relações entre os padrões de formação e distribuição da veia porta nesta espécie. Os animais foram injetados com látex Neoprene, fixados em formalina $10 \%$ e dissecados. A veia porta, na sua trajetória extraparenquimal, constituiu-se da junção da veia mesentérica cranial e caudal, recebendo ainda tributárias do estômago, baço e pâncreas. A veia mesentérica cranial formou-se, na totalidade dos casos a partir da confluência de um tronco jejunal e um tronco ileocecocólico. O tronco jejunal foi formado pela união de oito a dezoito veias jejunais e o tronco ileocecocólico constituiu-se a partir do encontro das veias cólicas, cecais e ileais, em diferentes arranjos e números. A veia mesentérica caudal foi formada pela união das veias retal e cólica esquerda.
\end{abstract}

\section{Introdução}

O coelho (Oryctolagus cuniculus Linnaeus, 1758) é um animal que se destaca pela intensidade do seu uso como animal de experimentação, o qual, ao longo de toda a história da medicina experimental, seja no âmbito da cirurgia, da farmacologia ou, principalmente, da imunologia, vem desempenhando papel de indiscutível relevância.

O componente venoso intestinal, que contribui para a formação da veia portahepática, juntamente com as tributárias venosas oriundas do baço, pâncreas e estômago, assume papel relevante quando analisado do ponto de vista do seu arranjo anatômico, em especial, quanto ao número e à expressão dos seus constituintes. Tal disposição é escassamente referida na literatura, sobre o coelho, e totalmente ausente quando o interesse passa a ser voltado para as diferentes raças, dentro desta mesma espécie animal.

\author{
Palavras-chave \\ Anatomia. \\ Coelhos. \\ Intestinos. \\ Veia porta-hepática.
}


Nos achados de Cooper e Schiller ${ }^{4}$ em cobaias (Cavia porcellus), citam que, a veia porta-hepática forma um sistema coletor de sangue dos vasos capilares da área gastrointestinal, em direção ao leito capilar hepático.

De acordo com $\mathrm{Cook}^{5}$, referindo-se ao camundongo de laboratório, a veia portahepática constitui-se a partir da confluência de vasos oriundos do estômago, baço e pâncreas e diversas partes do intestino delgado e grosso.

Quanto aos animais domésticos em geral numerosos são os autores que se dedicam ao tema, resultando registros como em Bruni e Zimmerl ${ }^{6}$, Getty ${ }^{7}$ e Smith ${ }^{8}$ discorrem sobre o sistema porta dos animais domésticos em geral; D'arce e Flechtmam ${ }^{9}$, Dyce, Sack e Wensing ${ }^{10}$ e Schröder e Krahmer ${ }^{11}$ nos mamíferos domésticos; Evans e Christensen ${ }^{12}$ e Frandson e Spurgeon ${ }^{13}$, em cães; e ainda Sisson e Grossman ${ }^{14}$ e Ghoshal, Kock e Popesco ${ }^{15}$, reportando-se ao cavalo.

\section{Materiais e Métodos}

Para a realização do presente trabalho, foram utilizados 20 (vinte) coelhos (Oryctolagus cuniculus) adultos, 11 machos e 09 fêmeas, da raça Nova Zelândia Branco. Esses animais, após a ortotanásia com superdose de anestésico (Thiopentax), e abertura, mediante incisão mediana, da cavidade abdominal, tiveram a sua veia porta canulada, onde foi injetada uma solução corada de Neoprene látex, utilizando-se seringa descartável e sob pressão manual moderada, até que se confirmasse, visualmente, a total repleção daquele sistema venoso portal extra-hepático. Após esses procedimentos os animais foram fixados, em solução aquosa de formol a 10\%, mantidos em recipiente contendo a mesma solução, até que pudessem ser dissecados. As dissecações foram realizadas com o emprego de instrumental cirúrgico e com o auxílio de lupa (aumento 4x), sendo acompanhadas pela elaboração de esquemas representativos dos diferentes arranjos vasculares, os quais prestaram-se às análises e documentação. Simultaneamente foram tomadas algumas imagens fotográficas, as quais dão suporte e ilustram a exposição dos resultados.

\section{Resultados}

A partirdas dissecações, esquematizações e fotografias, analisaram-se os arranjos vasculares relativos a cada parte do trato digestório da abrangência do sistema porta hepático.

\section{Tributárias da veia porta-hepática}

A veia porta no coelho da raça Nova Zelândia Branco é formada pela união de tributárias que drenam o estômago, duodeno, jejuno, íleo, ceco, cólons (maior, menor, direito, médio e esquerdo), reto, pâncreas e baço.

No material examinado, contribuem para a formação da veia porta-hepática os seguintes componentes venosos: a veia gastrolienal, a veia pancreaticoduodenal, tronco da veia jejunal, a veia mesentérica cranial, a veia cólica esquerda, a veia cólica direita, a veia cólica média e a veia mesentérica caudal.

Quanto às características de sua formação, bem como do seu território de drenagem, os componentes venosos formadores da veia porta-hepática se apresentam como se segue:

\section{Veia gastrolienal}

Nos 20 animais estudados, a veia gastrolienal estende-se caudalmente à direita, e é formada pela união das veias gástrica esquerda, gástrica direita e lienal. A veia lienal, que recebe ramos da região cárdica, passa paralelamente à face visceral do baço, onde recebe ramos lienais próprios. Por fim, esta veia recebe ramos oriundos da região fúndica do estômago, resultando na veia gastrolienal, que por sua vez recebe a veia gástrica esquerda, na curvatura maior do estômago. A veia gastrolienal desemboca na veia porta, próximo à entrada 
do fígado, dorsalmente ao processo caudado do lobo caudado.

\section{Veia pancreaticoduodenal}

A veia pancreaticoduodenal apresenta quatro disposições: em cinco animais $(25 \%)$ recebe, como tributárias, um ramo duodenal e o um ramo duodenojejunal, antes de sua desembocadura na veia porta-hepática. Em oito animais (40\%), a veia pancreaticoduo-

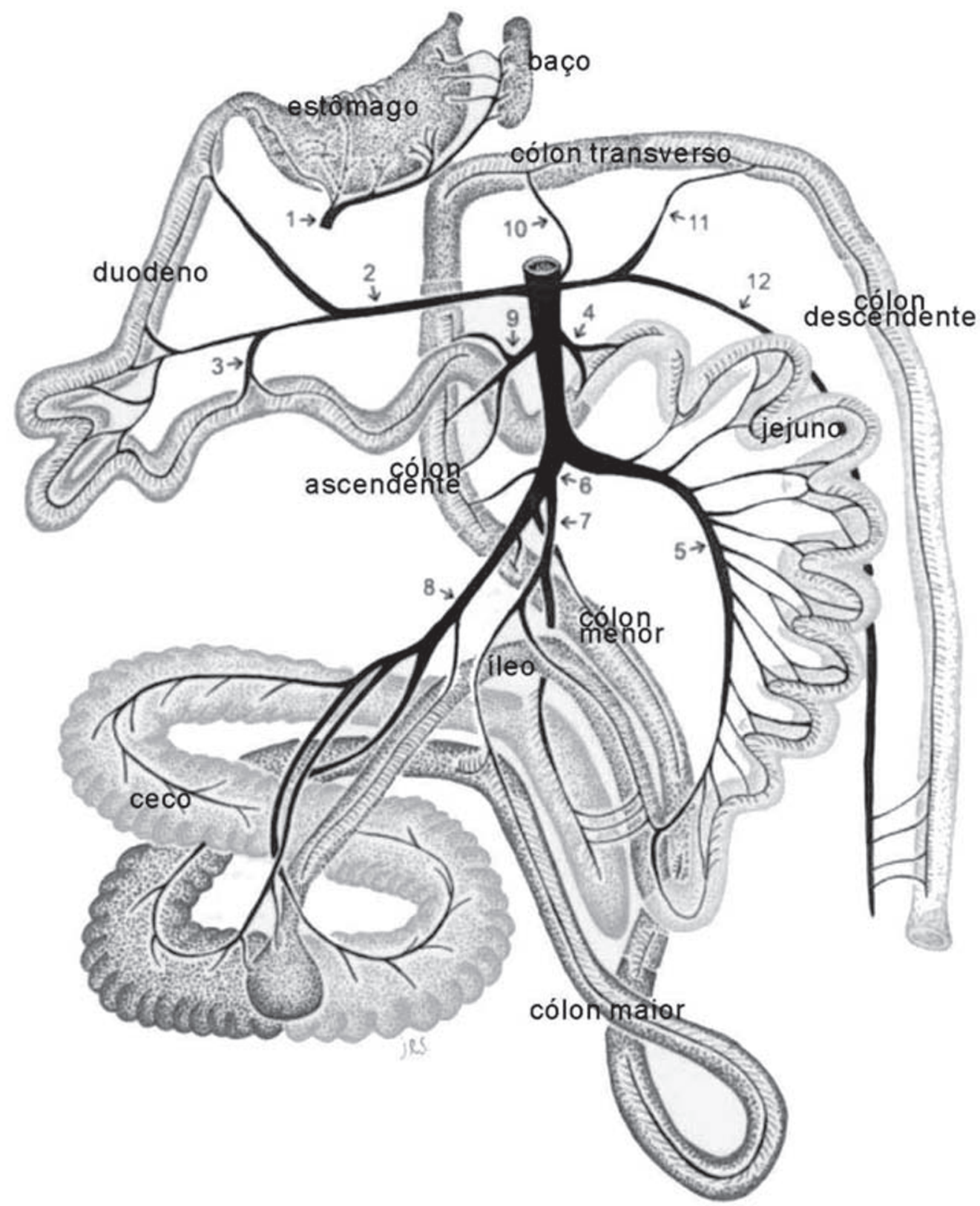

Figura 1 - Desenho esquemático evidenciando os componentes venosos formadores da veia porta-hepática no coelho (Oryctolagus cuniculus Linnaeus, 1758) da raça Nova Zelândia Branco. (1) veia gastrolienal, (2) veia pancreaticoduodenal, (3) ramo duodenal, (4) ramo duodenojejunal, (5) tronco jejunal, (6) veia mesentérica cranial, (7) tronco ileocecal, (8) tronco ileocecocólico, (9) veia cólica direita, (10) veia cólica média, (11) veia cólica esquerda, (12) veia mesentérica caudal 
denal recebe apenas o ramo duodenal e desemboca na veia porta-hepática, separadamente do ramo duodenojejunal. Em três animais $(15 \%)$, a veia pancreaticoduodenal não recebe os ramos duodenal e duodenojejunal que, por sua vez, formam um tronco comum, que desemboca na veia porta-hepática. Vale ressaltar ainda que, em quatro casos $(20 \%)$, os ramos duodenal e duodenojejunal confluíram, separadamente, para a veia porta-hepática.

\section{Veia Mesentérica Cranial}

A veia mesentérica cranial apresentouse sempre como a maior tributária do sistema venoso portal hepático. Situa-se à direita da artéria mesentérica cranial, acompanhando-a em grande parte e, comumente $(100 \%)$, recebe a veia jejunal, a veia pancreaticoduodenal, a veia mesentérica caudal e a veia ileocólica, antes de juntar-se á veia porta-hepática. A veia mesentérica cranial é constituída a partir do encontro dos troncos ileocecocólico e ileocecal. Em 12 casos $(60 \%)$ no entanto, o tronco ileocecal recebe um ramo cólico, resultando assim um segundo tronco ileocecocólico.

O primeiro tronco ileocecocólico é constituído por três ramos venosos: veia ileal, veia cólica (do cólon maior) e veia cecal. O segundo tronco ileocecocólico é constituído pela veia ileal, veia cecal e veia cólica (do cólon menor). Todos os animais estudados apresentam arcos anastomóticos entre as veias da porção final do ceco e da porção inicial do íleo, arcos esses também registrados entre a veia ileal e a veia jejunal. Em um animal (5\%), o primeiro tronco ileocecocólico é constituído pelas veias ileal, pela cecal e cólica maior e, nestes casos, a veia cólica maior apresenta numerosos arcos anastomóticos com a veia cecal. Em um animal, (5\%), o primeiro tronco ileocecocólico recebe além das veias já citadas, uma veia cólica menor, proveniente do segundo tronco ileocecocólico.

Em quatro animais (20\%), o segundo tronco ileocecocólico é formado pela união das veias ileal e cecal, além de veias que drenam parte do cólon maior. Em dois animais $(10 \%)$, o segundo tronco íleocecocólico é constituído pela junção das veias ileal, e cecal, além de veias que drenam parte do cólon menor. $\mathrm{Na}$ totalidade dos casos estudados (100\%), o ramo cólico, do primeiro tronco ileocecocólico continua pela parede do cólon maior, até formar anastomose com o ramo cecal daquele mesmo tronco.

\section{Tronco jejunal}

O tronco jejunal é formado pela união das veias jejunais, é a maior tributária da veia mesentérica cranial, em todos os animais. Recebe de oito a dezoito veias jejunais, sendo em maior número com oito ramos $(25 \%)$, doze ramos $(20 \%)$, dez e onze ramos $(15 \%)$, nove ramos $(10 \%)$ e quatorze, quinze e dezoito ramos $(5 \%)$. Para o tronco jejunal contribuem ainda, logo no seu início, as veias ileais, que drenam a parte final do íleo, bem como alguns ramos cecais, que estabelecem anastomoses com aquelas últimas.

\section{Veia cólica direita}

Em 17 animais (85\%), a veia cólica direita apresenta-se como um único vaso drenando o cólon ascendente. Em um animal (5\%), a veia cólica direita apresenta-se dupla drenando o cólon ascendente. Em dois animais $(10 \%)$, a veia cólica direita realiza anastomose com a veia cólica média e desemboca na veia porta-hepática.

\section{Veia cólica média}

Em 12 animais (65\%), a veia cólica média apresenta um único vaso, que drena o cólon transverso, e desemboca diretamente na veia porta-hepática. Em sete animais (35\%), as veias cólica média, cólica esquerda e mesentérica caudal formam um tronco comum, que desemboca na veia portahepática.

\section{Veia cólica esquerda}

Em 14 animais (70\%), a veia cólica esquerda forma um tronco comum com a 
veia mesentérica caudal que esta por sua vez desemboca na veia porta-hepática. Em cinco animais $(25 \%)$, a veia cólica média e veia cólica esquerda formam um tronco, que desemboca na veia mesentérica caudal que, por sua vez desemboca na veia portahepática. Em um animal (5\%), a veia cólica média e a veia cólica esquerda formam um tronco comum, que desemboca diretamente na veia porta-hepática.

\section{Veia mesentérica caudal}

A veia mesentérica caudal tem início a partir de um plexo venoso, situado junto à parede do reto, e corre paralelamente à artéria retal cranial, como veia retal cranial, que se une à veia mesentérica caudal. Seguindo uma trajetória cranial, essa veia recebe, em alguns casos, ramos das veias cólica esquerda e cólica média; Podendo ainda desembocar diretamente na veia portahepática, sem receber tributárias (5\%). Em um animal (5\%), a veia mesentérica caudal, antes de desembocar na veia porta, recebe um ramo da parte inicial do cólon descendente. Em dez animais (50\%), a veia cólica esquerda junta-se à veia mesentérica caudal e desemboca na veia porta-hepática. Em nove animais (45\%), a veia mesentérica caudal forma um tronco comum com as veias cólica média e cólica esquerda, que desemboca na veia porta-hepática.

\section{Discussão}

Quando nos referimos a veia porta extraparenquimal, Smith ${ }^{8}$, descreve que o sistema venoso portal hepático é uma série de veias nomeadas, que escoam a maioria da área digestiva (estômago, intestinos, pâncreas e baço). Quando analisamos os resultados obtidos em outras espécies 9,12,13,15, 14 nota-se que o sangue escoado do estômago, baço, intestinos e pâncreas é filtrado pelo fígado, antes de retornar a circulação geral.

De acordo com Bruni e Zimmerl ${ }^{6}$ a circulação portal é formada, a partir da confluência da veia mesentérica cranial e da veia esplênica, recebendo constantemente a veia gastroduodenal e ocasionalmente um vaso pancreático. Para Getty ${ }^{7}$ a veia gastroduodenal, ramos pancreáticos, a veia esplênica, a veia pancreaticaduodenal caudal e as veias mesentéricas cranial e caudal, são afluentes terminais da veia porta.

$\mathrm{Na}$ maioria de nossas preparações encontraram-se resultados semelhantes aos descritos por Dyce, Sack e Wensing ${ }^{10}$, confirmando que a veia porta é um vaso formado pela união de tributárias que drenam o estômago, duodeno, jejuno, íleo, ceco, cólons, reto, pâncreas e baço.

Analisando agora separadamente, cada ramo que participa da formação do tronco da veia porta, começaremos com a veia gastrolienal. Cooper e Schiller ${ }^{4}$, investigando a veia gastrolienal, na cobaia (Cavia porcellus), a qual segundo o autor, tem sua origem pela confluência do ramo tributário do baço e ramo pancreático, recebendo de três a quatro veias gástricas menores que escoam a curvatura maior do estômago a veia gástrica esquerda, que escoa a curvatura menor do estômago, formando um tronco comum com a veia gástrica direita, próximo ao piloro. Arranjo semelhante a este é encontrada na raça de coelho estudada.

Smith ${ }^{8}$, descreve nos animais domésticos que, a veia gastroduodenal é tributária da veia porta-hepática, entretanto esta desemboca a uma pequena distância cranial a veia esplênica. A veia gastroduodenal recebe a veia pancreaticoduodenal cranial, gastroepiploica direita e veias gástricas direita. Em roedores é descrito que a veia gastroduodenal é formada pela fusão da veia gastroepiploica direita que vem, da curvatura menor do estômago e da veia pancreaticoduodenal cranial, do duodeno, e partes adjacentes do pâncreas ${ }^{4,3}$.

Para Sisson e Grossman ${ }^{14}$, a veia pancreaticoduodenal desemboca diretamente na veia porta. Em nossos achados encontramos a veia gastroepiploica desembocando em todos os casos (100\%), diretamente na veia porta-hepática, e em 
separado da veia pancreaticoduodenal: em (20\%), dos casos o ramo pancreaticoduodenal recebe o ramo duodenal e o ramo duodenojejunal, formando um tronco e juntamente com o ramo pancreaticoduodenal desembocam na veia porta-hepática; em $(40 \%)$ dos casos, o ramo pancreaticoduodenal recebe o ramo duodenal e desembocam na veia porta-hepática separadamente do ramo duodenal; em (20\%) dos casos, o ramo pancreaticoduodenal não recebe nenhuma tributária, desembocando diretamente na veia porta-hepática, já o ramo duodenal e o ramo duodenojejunal formam um tronco comum e ambos desembocam na veia porta-hepática, já em (20\%) dos casos, o ramo pancreaticoduodenal, ramo duodenal e o ramo duodenojejunal desembocam todos em separado na veia porta-hepática.

A veia mesentérica cranial é constantemente a maior tributária do sistema venoso portal hepático e recebe tipicamente o tronco jejunal, a veia pancreaticoduodenal, a veia mesentérica caudal e a veia ileocólica antes de penetrar no parênquima hepático ${ }^{4}$, 1,11,8. Em nossas observações acrescentamos ainda que a veia mesentérica cranial recebe as tributárias da veia cólica direita, veia cólica média e veia cólica esquerda.

Um tronco ileocecocólico e um tronco intestinal juntam-se para formar a veia mesentérica que ainda recebe tributárias pancreáticas e uma veia pancreaticoduodenal caudal, aliás, o ramo pancreaticoduodenal caudal ${ }^{15}$ é um dos afluentes da veia mesentérica cranial. Entretanto, os arranjos formadores na constituição da veia mesentérica cranial são os mais diversos, tanto que de acordo com Ghoshal, Kock e Popesco ${ }^{15}$, os primeiros afluentes do citado vaso são os afluentes da veia pancreaticoduodenal e da veia cólica média. Posteriormente a veia mesentérica cranial recebe um tronco veia ileocólica, veia cólica direita e veia ileal, que drenan o cólon ascendente e o ceco.

A veia mesentérica caudal, considerada por Getty ${ }^{7}$ ramo da veia porta, recebe a veia cólica média (oriunda do cólon transverso e alça distal do cólon), a veia cólica esquerda (que é a continuação da veia cólica média no cólon descendente) e a veia retal cranial.

$\mathrm{Smith}^{8}$, descreve que a veia mesentérica caudal recebe uma porção da drenagem da veia cólica média e entra na veia mesentérica cranial em uma posição cranial, oposta a veia ileocólica.

Schwarze e Schröder ${ }^{16}$, citam que, a veia mesentérica caudal acompanha a artéria correspondente e se ramifica, em geral, como esta recebe também a veia cólica média.

$\mathrm{Na}$ cobaia $^{4}$ a veia mesentérica caudal começa como um plexo venoso ao redor do reto, e corre paralela à artéria retal cranial como a veia retal cranial que anastomosa-se com a caudal e veias retais medianas. A veia retal cranial corre cranialmente dentro do mesentério do cólon descendente como a veia cólica esquerda e entra dorsolateralmente defronte a veia porta e a veia pancreaticoduodenal caudal.

Particularmente as veias cólicas são consideradas por alguns autores como parte do tronco ileocecocólico ${ }^{6}$ ou ileocólico ${ }^{15}$ têm disposição variada, ou seja, a veia cólica média anastomosa-se com a veia cólica direita e a veia cólica esquerda continua-se com a veia retal cranial que se anastomosa com a veia retal caudal.

Em nossas dissecações encontramos a veia mesentérica caudal iniciando sob o reto por grossos ramos hemorroidários, dirigindo-se cranialmente entre duas lâminas mesentérica e cólica, para mais tarde unir-se em dez casos $(50 \%)$ com a veia cólica esquerda, em nove casos (45\%) com a veia cólica esquerda e a veia cólica média, e em seguida desembocam na veia mesentérica cranial para formar a veia porta-hepática. Verificamos ainda em nossos resultados que a veia responsável pela drenagem do cólon terminal chega independentemente na veia mesentérica cranial em um caso $(5 \%)$.

Foram vistas também anastomoses entre os ramos da veia cólica média com a veia cólica direita em três casos $(15 \%)$. Ao final do jejuno as veias que drenam aquela 
porção do intestino anastomosam-se com as veias ileais e estas com as veias que drenam a porção final do ceco.

\section{Conclusão}

Do que acabamos de expor podemos concluir que:

A veia porta-hepática constitui-se após a junção das veias mesentéricas cranial e caudal; recebendo ainda tributárias provenientes do estômago, baço e pâncreas;

A veia mesentérica cranial forma-se de um tronco jejunal comum e um tronco ileocólico; o tronco jejunal comum é formado pela união de oito a dezoito veias jejunais; o tronco ileocecocólico, por sua vez, é constituído após o encontro das veias cólicas, cecais e ileais, em diferentes arranjos e número;

A veia mesentérica caudal é formada pela reunião das veias retal e cólica esquerda, que por sua vez estabelecem arco anastomótico comum ao longo da parede do cólon descendente;

Como tributárias da veia portahepática, observam-se, uma veia jejunal, uma veia duodenojejunal, uma veia cólica direita, uma veia cólica média, uma veia pancreaticoduodenal.

\title{
The hepatic-portal vein in rabbits of White New Zeland bredd (Oryctolagus cuniculus Linnaeus, 1758)
}

\begin{abstract}
Considering the shortage of information in the literature, it is looked for to draw a profile of formation of the portal vein in twenty rabbits, to recognize the distribution pattern, looking for evidences of possible correlation between the formation patterns and the distribution of the portal vein. The animals were injected by Neoprene latex, fixed in formalin $10 \%$ and dissected. The hepatic-portal vein, in it extraparenquimal trajectory, was constituted, for the junction of the cranial and caudal mesenteric veins and receives veins from the stomach, spleen and pancreas. The cranial mesenteric vein receives, in all cases, a jejunal and an ileocecocolic trunk. The jejunal trunk was formed by the junction from eight to eighteen jejunal veins. The ileocecocolic trunk was formed by the encounter of the colic, cecals and ileal veins, in different arranjements and numbers. The caudal mesenteric vein was formed by junction of the rectal and left colic veins.
\end{abstract}

Key-words: Anatomy. Rabbits. Intestine. Portal vein.

\section{Referências}

1 HEATH, T.; HOUSE, B. Origin and distribution of portal blood in the cat and rabbit. American Journal of Anatomy, v. 127, n. 2, p. 71-80, 1970.

2 BARONE, R. et al. Atlas d' anatomie du lapin. Paris: Masson, 1973, p. 138.

3 HEBEL, R.; STROMBERG, M. V. Anatomy and embriology of the laboratory rat. London: Bio Med Verlag Wort hessee, 1982. p. 113.

4 COOPER, G.; SCHILLER, A. L. Anatomy of the guinea pig. Cambridge: Harvard University Press, 1975. p. 167-168.

5 COOK, M. J. The anatomy of laboratory mouse.
London: Academic Press, 1965. p. 93-95.

6 BRUNI, A.; ZIMMERL, A. U. Anatomi degli animali domestici. Milano: Francesco Vallardi,1946. v. 1-2. p. 80-382.

7 GETTY, R. Sisson/Grossman: anatomia dos animais domésticos. 5. ed. Rio de Janeiro: Guanabara Koogan. 1986. v. 2, p. 1137-2000.

8 SMITH, B. J. Canine anatomy. Philadelphia: Williams \& Wilkins, 1999. p. 429. (The national veterinary medical series).

9 D'ARCE, R. D.; FLECHTMANN, C. H. W. Introdução à anatomia e fisiologia animal. São Paulo: Nobel, 1980. p. 103-104.

10 DYCE, K. M.; SACK, W. O.; WENSING, G. J. G. 
Tratado de anatomia veterinária. Rio de Janeiro: Guanabara Koogan, 1990. p. 89.

11 SCHRÖDER, L.; KRAHMER, R. Anatomia de los animales domesticos. Zaragoza: Acriba. 1979. p. 144.

12 EVANS, H. E.; CHRISTENSEN, G. C. Miller's Anatomy of the dog. 2 ed. Philadelphia: W. B. Saunders, 1979. p. 497-498.

13 FRANDSON, R. D.; SPURGEON, T. L. Anatomy and physiology of farm animals. 5 th ed. Philadelphia: Williams \& Wilkins. 1992. p. 259-260.

14 SISSON, S.; GROSSMAN, J. D. Anatomia de los animales domesticos. 4. ed. Barcelona: Salvat, 1973. p. 685-686.

15 GHOSHAL, N. G.; KOCK, T.; POPESCO, P. The venous drainage of the domestic animals. Philadelphia: W. B. Saunders, 1981. p.143-149.

16 SCHWARZE, E.; SCHRÖDER, L. Compendio de anatomia veterinaria. Zaragoza: Acribia, 1972, v. 5, p. 102-105. 